\title{
VULLIAMY E BRAQUE POR FRANCIS PONGE
}

\section{VULLIAMY AND BRAQUE BY FRANCIS PONGE}

\author{
Roseli de Fátima D. A. BARBOSA ${ }^{26}$
}

\begin{abstract}
RESUMO: Este trabalho apresenta um estudo sobre as marcas pictóricas presentes em dois textos de Francis Ponge, um sobre o pintor Gérard Vulliamy e o outro sobre o pintor Georges Braque. Esse poeta francês relacionou-se com e escreveu sobre grandes artistas plásticos durante sua vida. A intenção é estudar como se apresentam essas marcas das artes plásticas nesses textos e revelar quais os recursos usados pelo poeta para fazê-los, mostrando como essa relação se constrói literariamente na pena de Ponge.
\end{abstract}

PALAVRAS-CHAVE: Poesia francesa; Francis Ponge; Pintura; Gérard Vulliamy; Georges Braque.

ABSTRACT: This work presents a study on pictorial features in two texts by Francis Ponge, the first one about the painter Gérard Vulliamy, and the second, about the painter Georges Braque. Ponge established close relationships and wrote about great artists of his time. Our intention is to reveal how these features operate in the two texts by showing the linguistic resources Ponge uses to talk about the painters.

KEYWORDS: French poetry; Francis Ponge; Painting; Gérard Vulliamy; Georges Braque

\section{Relações entre a arte plástica e a literatura}

Durante séculos pintores se inspiravam na literatura para seus quadros e os escritores tentavam colocar os quadros diante dos leitores através das palavras. Entre os teóricos da Antiguidade, a pintura era esporadicamente comparada à poesia. Depreendese essa comparação, antecipada no poeta grego Simônides de Ceos (PRAZ, 1982, p.23), nos versos de Ars Poetica do latino Horácio (1988, p.361-365):

\footnotetext{
${ }^{26}$ Departamento de Teoria e História Literária - IEL - Universidade Estadual de Campinas (UNICAMP) - Campinas - SP - CEP 13083-859 - Brasil - roselie123@ hotmail.com
} 


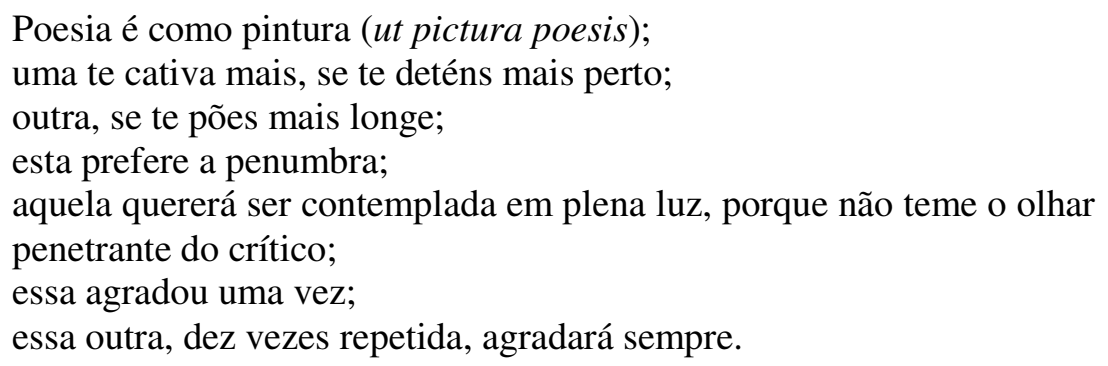

Segundo Charles Le Brun (1619-1690), um dos continuadores da reflexão sobre a relação pictura e poesis, a possibilidade de transposições entre as Artes é explicada porque as ideias são universais, apenas as palavras mudam de língua para língua, o que garante a traduzibilidade absoluta entre as artes, abrindo assim a possibilidade para o $u t$ pictura poesis (LESSING, 1998, p.16). A relação entre ideias e palavras se encontra na expressão da teoria da tradução, belles infidèles: "o texto de chegada é belo porque ele pode adaptar a mensagem do texto de partida completamente à língua de chegada; mas ele é infiel apenas com relação à forma do texto de partida." (LESSING, 1998, p.16).

Pode-se notar como o belo é associado à razão e ao logos universais, pois toda pessoa é dotada de razão. No que diz respeito à pintura, Le Brun valoriza mais o desenho do que a cor, sendo aquele associado à linha lógica do pensamento e essa outra apenas um ornamento (LESSING, 1998, p.16). Vasari (1511-1574) também via a pintura como aquela que provinha da arte do desenho (LICHTENSTEIN, 2006, p.11), essencialmente do intelecto (também o são as demais artes visuais, a arquitetura e a escultura). Na palavra disegno tem-se o duplo sentido de concepção e contorno, o projeto, o planejamento do que se quer fazer e a execução manual dos traços ${ }^{27}$. Para Vasari, o desenho tem dois aspectos: o teórico e o prático. Como fonte da invenção pictórica "confere à pintura a dignidade de uma atividade intelectual." Sendo assim, a pintura nasce do desenho. Zuccaro (1529-1566) escreve na Idea del pittore que o desenho é forma, concepção, ideia, regra e finalidade, tratando-se de uma atividade superior do intelecto (LICHTENSTEIN, 2006, p.12). Portanto, com o desenho, pode-se chegar ao conhecimento da anatomia, da história e da perspectiva. A importância do desenho aqui é tão grande que se fala em "narrar com pincel", referindo-se aos quadros

\footnotetext{
${ }^{27}$ Até o século XVII esse duplo sentido, em francês, era designado pela palavra dessein (desígnio) que significava desenho e ideia. Atualmente é distinguido no francês escrito dessin (desenho) e dessein (projeto). Assim também ocorre no inglês a distinção entre drawing e design (LICHTENSTEIN, 2006, p.19).
} 
históricos. O que aproxima o desenho do trabalho de escrita, pela sua relação com o intelecto.

Referindo-nos a tempos mais próximos dos nossos, vemos em Yves Bonnefoy um poeta que fornece um exemplo típico dessa relação entre literatura e pintura. Ele mesmo discorre sobre a ut pictura poesis como forma de buscar um lugar-comum da expressão do poético, um analogon (KUNZ, 1997 apud LESSING, 1998, p.469-473) entre o mundo natural e o da obra (BONNEFOY, 2005, p.16), embora alerte que a comparação entre poesia e pintura não supõe que os meios de expressão da pintura e da poesia tenham a mesma eficácia, provoquem efeitos idênticos em natureza ou grau da visão imediata, da mímesis. Para Bonnefoy o que os poetas somente poderiam dizer pela lembrança, recorrendo à memória, os pintores conseguem realizar de maneira menos verbalizada, e por vezes imediata em alguns exemplos notáveis (BONNEFOY, 2005, p.46-47). Como não perceber aqui um retorno ao tema do paragone que favorece a pintura no pincel de Da Vinci?

Vemos no poeta Francis Ponge uma maneira ainda mais extrema desse exemplo, pois usa de cada objeto para expô-lo na forma escrita como um quadro. Não utiliza cada objeto simplesmente para que esse faça parte de um décor, mas para ser o centro do poema, como que o ponto focal. Assim, Le parti pris des choses (PONGE, 1942) pode ser visto como uma galeria em que o autor trata cada objeto dispondo-o à maneira de uma exposição, cada um com sua linguagem, seu tratamento visual e verbal.

O trabalho de Ponge se dá no campo da descrição-definição, procurando exaustivamente a fórmula mais clara para falar sobre seus queridos objetos ou assuntos de preferência. Para tal reflexão faz uso do Littré, dicionário que é seu favorito, onde pode encontrar a melhor maneira de descrever e refletir sobre seus objetos. Para ele, à medida que trabalha seus textos, a linguagem contribui para a descoberta de novos dizeres. Essa mesma linguagem reage, propõe novas soluções e o leva para novas ideias. Parece ser um trabalho que faz do ato de pensar sua proposta e a partir daí o dicionário parece ser uma consequência, um outro objeto atrelado àqueles de que faz uso para a reflexão. Parece que trabalha dessa forma: primeiro coloca o objeto como o centro de sua atenção, espantando qualquer outra preocupação que por ventura venha se opor no momento. Segundo, escreve sobre seu trabalho, que abre um certo alçapão em 
seu espírito, se coloca aí para pensar inocentemente e com "muito amor, isto é, com fervor" (PONGE, 1961, p.29).

Os temas que Ponge escolhe são o ponto de partida para chegar aos verdadeiros objetos, às palavras, que quer materializar. Em Ponge as palavras também são uma coisa, o que aproxima seu trabalho das artes plásticas (CAPLLONCH, 2009, p.311). De certa forma leva o objeto até a palavra e, no mesmo sentido, a palavra até o objeto. $\mathrm{O}$ autor tem por ambição representar o real (PIERROT, 1993, p.458) e para isso dá muita importância à etimologia, que o leva a ponderar, digamos assim, tudo da palavra, "leurs racines, qui me semblent un peu comme 'le tronc' des mots, comme le noud de leur être, leur noyau, leur partie la plus essentielle et la plus dure, la plus solide (Pour un Malherbe, p.187)”. (PONGE apud CAPLLONCH, 2009, p.311). Neste artigo interessamo-nos pelo estudo de marcas pictóricas nos textos de Ponge.

Durante sua vida o poeta travou conhecimento e se relacionou com vários artistas plásticos, entre eles Braque, Picasso, Vulliamy e outros. “[...] Braque ou Picasso [eram] representantes de uma corrente artística com a qual o poeta se identifica muito mais do que com a de Breton” (MOTTA, 2000, p.18). Dessas amizades surgiram vários textos e livros em que Ponge escreve sobre os artistas. Tais textos se dão a reflexões sobre a sua escrita e as marcas pictóricas que o poeta francês deixou nos mesmos. Ponge refletiu e escreveu sobre a obra de grandes pintores, desenhistas e escultores como Braque, Fautrier, Dubuffet, Richier, Kermadec, Vulliamy, Picq, Giacometti, passando a elaborar numerosos textos sobre as obras e os materiais dos artistas. Vemos também o retorno desses pintores nas obras do poeta, sendo que alguns deles, como Braque, Dubuffet, Fautrier, Kermadec e Vulliamy, ilustraram alguns de seus poemas (e.g., Francis Ponge un poète, Proêmes, Braque - dessins).

Neste artigo vamos apresentar um estudo sobre o pintor suíço Gérard Vulliamy e sobre um dos criadores do Cubismo, o francês Georges Braque. A escolha dos dois autores é motivada não pela História da Arte, visto o papel majoritário do segundo artista nesse contexto, mas por permitir revelar procedimentos similares nos dois textos de Ponge, bem como assinalar a forma como o poeta francês participa da vida artística de seu tempo.

O objetivo deste estudo é o de apontar, precisamente, os recursos e marcadores textuais nos textos de Ponge que revelam elementos pictóricos no campo lexical 
(palavras e expressões específicas), no campo gráfico, no campo onomástico (nomes de quadros, de artistas), nos procedimentos da escrita, em suma, de que forma esses procedimentos se constroem literariamente no lápis de Ponge. A hipótese que defendo é a de que, a partir de uma atitude de espectador, a forma como Ponge torna presente as artes plásticas em sua obra permite dizer que o escritor se apropria da função de pintor empregando os materiais de um escritor de seu tempo para marcar pictoricamente sua escrita.

\section{Referência e alusão pictóricas}

De acordo com Vouilloux (2005), podemos identificar duas famílias de enunciados susceptíveis de dizer algo sobre a imagem: os referenciais e os alusivos. Os referenciais são exemplificados pelo nome do autor e o nome dos títulos dos quadros, entre outras referências diretas a obra e artista. O nome do autor, sendo o nome próprio, por si só não se traduz, está inscrito no grupo dos signos que “[...] circula[m] inalterável[eis] de uma língua para outra" (VOUILLOUX, 2005, p.25). O título pode ser traduzido e está no grupo que pertence ao campo do catálogo, do arquivo. Por ser título, às vezes recebe marcas tipográficas distintas como letra maiúscula, aspas, itálico etc., como exemplificado no poema seguinte, L'Imparfait ou Les Poissons-volants (PONGE, 1948, p.133):

L'I M P A R F A I T

ou

LES POISSONB-VOLANTS

La scène est au-dessus des eaux.

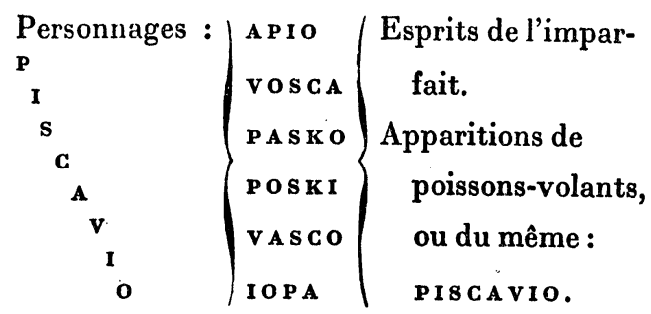

A P IO 
Os enunciados alusivos carregam um elemento importante que é a descrição. Dessa descrição podem-se reconhecer duas vertentes: primeiro temos os denominadores que seriam os substantivos que vão designar os pintores e a obra, tais como "artista", "pintor", "mestre", "quadro", "tela", "cor", "tinta", "retrato", "paisagem" e muitos outros. Segundo, temos as notações descritivas que variam do simples uso de adjetivos aos comentários em torno da pintura.

Enquanto o elemento-chave da referência é o símbolo, o qual fica imóvel em torno do que refere, a alusão nos leva a um caminho de analogias que não se esgota. $O$ nome pode fazer parte do alusivo com a condição de que os nomes-referência aos quais remete sejam implícitos para que o leitor possa interpretar, isto é, remontar à sua forma própria original. É o caso de Manneret que faz alusão a Manet e a Man Ray, na obra $L a$ Maison de rendez-vous de Alain Robbe-Grillet (VOUILLOUX, 2005, p.28).

Para Vouilloux, o "quadro" textual é aquele que ao citar outros, entre aspas, está acolhendo outros textos. À questão de onde começa o texto segue-se a questão de onde começa o livro que contém o texto. Ponge, ao sair do ateliê da escrita para entrar no ateliê do pintor, abre um caminho em que o quadro pintado é contemplado pelo escritor, o qual é estudado e posto em forma de texto, que por sua vez o leitor lê. Lendo-o, o leitor faz o sentido inverso, daquele do escritor, para chegar ao quadro, como comenta Vouilloux (2005, p.23).

Sendo assim, entre o espectador e o quadro, há sempre a linguagem, mesmo que aquele ainda não fale, mas seu olhar se encontra "prescrito", "pré-escrito" (VOUILLOUX, 2005, p.23). Exemplos singulares de enunciado referencial e alusivo são os textos de Ponge sobre Vulliamy e Braque.

\section{Marcas pictóricas no poema Prose sur le nom de Vulliamy de Francis Ponge}

Prose sur le nom de Vulliamy (PONGE, 1948, p.157-60), tem o nome do artista como referencial, mas não se esgota nessa referência, é um texto aberto a múltiplas maneiras de colocar esse mesmo nome também no plano alusivo. De fato, o poeta atrela o nome do pintor com palavras cujos aspectos de sonoridade são parecidos com o nome do pintor e cujos adjetivos fazem um elogio à pessoa de Vulliamy. Vejamos: 
Que nôtre pour des raisons diverses Vulliamy veuille tels mots ici que notre plume lia mis, quels mettrai-je sinon que dans l'oeil du mille j'ai rarement vu mettre le doigt, maître Gerard, comme tu l'y as mis.

Par goût de la volubilité alliée à de l'ironie nous ne te lâcherons plus, notre Vulliamy, pourvu, parce que tu vis dans la jungle en famille non loin du meilleur goût et de la plus fameuse poésie, que tu ne lances pas trop négligemment ton lasso dans ce siècle-ci.

Voilà donc ou plutôt vullia un ami (vullia mis ici, c'est, s'il est lu hardiment, plus que juste, et si clair même que je l'aime ainsi) ; vullia donc un ami doué, adroit, sensible dont, s'il prétend à lui, et c'est peut-être à quoi je puis lui être utile en préférant d'abord qu'il ne nous émerveille, je m'étonnerais fort qu'il ne nous ymarvuille.

Violence et vaillance encore lui refuserons-nous au profit (qui n'en est pas loin) d'une vuillance, que pour ce qu'elle en diffère je leur prefère.

De la voyance enfin à la vuillance s'il n'est qu'un poete tout seul puisse faire franchir, puisque Francis du moins fit qu'à la fin tu l'oses, vulliamment à ton tour franchis-le, mon ami.

"Prosa sobre o nome de Vulliamy" (tradução minha):

Que nosso, por razões diversas, Vulliamy queira tais palavras aqui que nossa pluma lia mis, quais colocaria eu senão que no olho do mil raramente vi colocar o dedo, mestre Gérard, como você l'y as mis.

Por gosto da volubilidade aliada ao da ironia não te deixaremos mais, nosso Vulliamy, desde que não lance muito negligentemente teu laço nesse século, porque você vive na selva em família não longe do melhor gosto e da mais famosa poesia.

Voilà, portanto, ou de preferência vullia un ami (vullia mis aqui, é, se é lido ousadamente, mais que justo, e mesmo tão claro que gosto dele assim); vullia portanto um amigo dotado, hábil, sensível, com qual, se ele se pretende, e é talvez em que posso lhe ser útil preferindo antes de tudo que ele nos maravilhe, muito me admirarei que ele nos ymarvuille.

Violência e valentia ainda lhe recusaremos ao proveito (quem não está longe nisso) de uma vulliance, que pelo que nisso difere as prefiro.

Da vidência enfim a sua vulliance se é somente um passo, que um poeta sozinho possa fazer superar, visto que Francis ao menos fez com que no final você ouse, vulliamment por sua vez superá-lo, meu amigo. 
Nesse texto o poeta se apropria da palavra e nome Vulliamy, marca pictórica relativa ao nome do pintor: a referência, nos termos de Vouilloux. Dessa referência Ponge tece considerações sem mencionar os quadros desse pintor e sem utilizar outras marcas pictóricas senão aquela da palavra maître, mestre, aquele que pode também ensinar a pintura, o seu trabalho. O nome-referência transforma-se em alusão porque o nome é ressubstantivado e invocado de diferentes formas, conforme veremos.

Do nome Vulliamy, Ponge se aproveita da partícula lia com o verbo mis (colocou), verbo mettre no passado, sugerindo assim que partícula e verbo participam do nome do pintor pela sonoridade (que notre plume lia mis). E novamente, no final desse primeiro parágrafo aparece l'y as mis (aí o colocou), com a mesma sonoridade da frase de cima (lia mis = l'y as mis).

O segundo parágrafo é desenvolvido com o nome todo do pintor, como referência. No parágrafo seguinte, Ponge transforma a palavra e nome Vulliamy em amigo (Vulli-amy $\rightarrow$ ami), ressaltando a sonoridade que o nome sugere (vullia un ami). De Vulliamy para Vullia un ami, voilà un ami (eis um amigo), deduzido de Voilà donc ou plutôt un ami, orientando o leitor como interpretar a partícula vullia. Usando o $V$, o $l$ e o $a$, em Vullia - voilà o nome é tomado como advérbio.

O nome também é ressignificado, da palavra émerveille tem-se ymarvuille, que também faz seu retorno ao nome, pois de vulli tem-se vuille continuando assim a trabalhar com a sonoridade. Observe-se também que a sequência de consoantes é a mesma e, das vogais do nome Vulliamy, tomam-se as mais próximas da palavra émerveille para ocupar o lugar das vogais dessa.

No parágrafo seguinte, do nome, mais uma vez ressignificado, vemos os substantivos violence (violência) e vaillance (valentia). Vaillance se transforma em vulliance e desse substantivo passa para voyance (vidência) em que Ponge se coloca no fim do poema não como a esponja, éponge (esponja) de seu poema A laranja (PONGE, 2000, p.67), mas como a coragem para franchir, de Francis, para ultrapassar, pedindo ao pintor que ultrapasse valentemente, vulliamment, ousando ser o que ele é. Seu nome como assinatura, Francis, no final do texto fecha-o assim como o pintor coloca no final sua assinatura no quadro. Esse tipo de jogo é comum na pena de Ponge, pois muitas vezes coloca seu nome transformado ou não em seus textos. Como, por exemplo, na Figue, em Braque le réconciliateur, que veremos a seguir. 


\section{Marcas pictóricas no poema Braque le réconciliateur de Francis Ponge}

Ponge transformou o referencial em discurso alusivo usando o nome de Georges Braque para criar seu texto em Braque le réconciliateur (PONGE, 1948, p.115-40), que prefacia um conjunto de reproduções de desenhos do artista. Vejamos:

Braque le réconciliateur

[...] Puisque ces pages que tu t'apprêtes, les lisant ou non,

[...] [rideau] - épaissi de mes propres couleurs.

[...], Braque pour moi, eh bien, se situe à peu près à égale distance de Bach, prononcé à la française, et de Baroque, - avec une légère attraction du second côté à cause de l'adjectif commun Braque, lequel existe bien aussi, je n'y peux rien, et présente quelque rapport de sens avec Baroque; selon lesquelles [mes authentiques opinions] encore le bon chien fruste et plutôt grave et très fidèle qui porte le même nom intervient bientôt alentour, comme aussi ces Barques (retournées dès lors sur le sable) qui peuvent très bien être peintes de toutes sortes de couleurs vives, elles n'en sont pas moins plutôt marron, comme est le bois em général, qu'il s'agisse de celui des hangars ou des granges dans la campagne verte ou des boiseries de salles à manger, des lutrins, des tribunes d'orgues ou simplement des violons ou des guitarres, - à la moitié droite, c'est-à-dire gauche desquels ressemble indiscutablement beaucoup le B initial du nom de notre grand homme, tandis que le $Q$ avec son manche évoque irrésistiblement soit une casserole de terre, soit une cuiller à pot, soit un mirroir à main, - et que l'A de son unique syllabe sonnante sonne ouvert et grave, comme brame la rame...

[...] Or il se trouve justement que nous sommes " gorgés d'éléments naturels ", d'impressions sensorielles, gorgés dès l'enfance.

[...] (épaisse, colorée),

[...] artistes pressés, et qui est de prendre à la nature ses éléments. C'est ainsi qu'il leur arrive d'aller chercher, comme l'hirondelle la paille, n'importe quoi pour faire leur nid. Papiers collés, fils de fer, bribes de conversation, lieux communs.

[...] Puisque, nous le voyons bien, nous faisons des tableaux, faisons des tableaux, faisons de la peinture. Nous aurons la peau de la peinture à l'huile en la traitant d'une certaine façon.

[...] Il se trouve que le marron et plusieurs autres couleurs fondamentales: celle des portants de bois, des labours, de la végétation, le noir des fourneaux, le blanc-bleu des nuages avaient besoin d'être un peu domptés, d'être répartis un peu plus sérieusement que dans la nature; pour notre aise, notre confort. Et je dirai la même chose des formes: les voilà toutes, je parle des plus familières, recoupées à notre mesure, celle de ce que nous nous attendons bien (car nous sommes sages) à rencontrer là: des tableaux, de dimensions moyennes. C'est à tel point que dans une exposition où ne figure aucun Braque nous avons toujours tendance à nous 
approcher de la fenêtre, si par hasard il y en a une, ou à défaut de fenêtre, de toute autre chose: le bureau du directeur par exemple.

[...] Et je n'aurai pas besoin de l'expliquer davantage, si je cite à la suite les noms de [...]; de Poussin, Chardin, Cézanne et Braque.

"Braque o reconciliador" (tradução minha):

Visto que essas páginas que você prepara, lendo-as ou não,

[...] [cortina] - espessada com minhas próprias tintas.

[...], Braque para mim, pois bem, se situa um pouco a igual distância de Bach, pronunciado à francesa, e de Baroque, - com uma ligeira atração do segundo lado por causa do adjetivo comum Braque, o qual existe também, não posso fazer nada, e apresenta alguma relação de sentido com Baroque; segundo as quais [minhas autênticas opiniões] ainda o bom cachorro rude e de preferência grave e muito fiel que leva o mesmo nome intervém logo dos arredores, como também essas Barques (viradas desde então sobre a areia) que podem muito bem ser pintadas com todas as cores vivas, elas não são, de preferência, menos marrom, como é a madeira em geral, quer se trate daquela dos depósitos ou das granjas no campo verde ou dos amadeiramentos de salas de jantar, das estantes, das tribunas dos órgãos ou simplesmente dos violinos ou dos violões, com a metade direita, isto é, esquerda dos quais se parecem indiscutivelmente, muito, com o B inicial do nome de nosso grande homem, enquanto o Q com seu cabo evoca irresistivelmente, seja uma caçarola de barro, seja uma colher de tigela, seja um espelho de mão, e que o A de sua única sílaba soante soa aberta e grave como brama o remo...

[...] Ora, acontece justamente que somos "encharcados de elementos naturais", de impressões sensoriais, encharcados desde a infância.

[...] (espessa, colorida),

[...] artistas apressados e que são de tomar da natureza seus elementos. É assim que lhe acontece de ir procurar, como a andorinha a palha, não importa o que para fazer seu ninho. Papéis colados, fios de ferro, pedacinhos de conversa, lugares comuns.

[...] Visto que, nós o vemos bem, nós fazemos quadros, fazemos quadros, pintamos. Nós teremos a pele da pintura a óleo tratando-a de uma certa maneira.

[...] Acontece que o marrom e várias outras cores fundamentais: aquela das alças de madeira, das terras aradas, da vegetação, o negro dos fornos, o branco azulado das nuvens tinham necessidade de ser um pouco domados, de serem repartidos um pouco mais seriamente que na natureza; para nosso bem estar, nosso conforto. E eu diria a mesma coisa das formas: ei-las todas, falo das mais familiares, recortadas à nossa medida, aquela que esperamos bem (pois somos ajuizados) encontrar aqui: quadros com dimensões medianas. É a tal ponto que numa exposição onde não há nenhum Braque temos a tendência a nos aproximar da janela, si por sorte há uma, ou, na falta de janela, de qualquer outra coisa: a mesa do diretor por exemplo.

[...] E não teria necessidade de explicar mais, se cito em seguida os nomes de [...]; de Poussin, Chardin, Cézanne e Braque. 
Nesse texto, parece que o poeta traça alguns esboços ou pincela com suas tintas seu modelo que é Braque. Aqui, o autor situa Braque paralelamente com Bach "pronunciado à la française” (“bak”), com Baroque, com barques pintadas com cores vivas, de madeira, marrons como o bois, da madeira dos celeiros no campo, do madeiramento das salas, das estantes, dos violinos ou violões. Os marcadores textuais da descrição pictórica são explícitos aqui, tanto pela escolha lexical, o alusivo desenvolvido em forma de substantivos e adjetivos, quanto pelo nome do artista, o referencial. Até o nome do pintor é adjetivado pelo poeta. Violinos e violões são instrumentos que se parecem com a letra $\mathrm{B}$, aquele do nome do pintor, o $\mathrm{Q}$ de seu nome evoca uma caçarola de barro com cabo, uma tigela com colher ou ainda um espelho de mão e o A, em única sílaba aberta e sonora, carrega o som do remo em movimento (barques).

O nome é sentido como Bach primeiramente, a um nome clássico da música pronunciado de uma certa maneira, à francesa, feito " $k$ " na última sílaba, depois o nome é ligado a um certo tipo de pintura, à barroca e por último leva-o a pensar nas barcas, aquelas que estão viradas na praia e não somente nas coloridas, mas também nas marrons pela cor da tinta ou da madeira da barca. Todos os três nomes têm a última sílaba pronunciada da mesma maneira.

À plasticidade do nome do pintor, ele atrela objetos, aqueles que fazem lembrar as letras do nome. Assim o A quase centralizado é o remo, o que impulsiona a barca Braque a seguir adiante, a traçar na água o caminho que deve seguir.

Então Braque com seu B em forma de violinos e violões evoca também na forma a música clássica, o compositor Bach. Com a letra Q se transporta para o campo, onde o objeto caçarola é aquele que é utilizado no dia-a-dia. Podemos imaginar que o R, o U e o E são o complemento para os instrumentos musicais serem tocados, são o alimento ou os adornos para a caçarola, são qualquer coisa que possa fazer mais confortável a viagem na barca.

Depois se percebe que o pintor está "encharcado" de impressões, aquelas também dos impressionistas com seus campos, seus objetos e suas marinas com barcas viradas ou desviradas. Seu colorido ora espesso pelas pinceladas, carregadas de tinta, sobrepostas, mostrando o colorido das tintas bem escolhidas. Embora haja essa alusão, o termo impressionismo não se aplica propriamente a Braque, senão como afastamento. 
Aqui aconteceu também de o pintor ser comparado à andorinha; assim como esse passarinho recolhe galhinhos, gravetinhos e outras coisinhas para seu ninho, o pintor também recolhe pedaços de papel, de ferro e outros objetos para fabricar a sua obra, aquela dos cubistas, elaborada por fragmentos. E os pedacinhos de conversa, que também fazem parte dessa obra-ninho, podem ser aqueles dos intervalos, entre o trabalho e o descanso, em que o pintor se entretém com uma boa conversa entre amigos. Assim obra e ninho muito bem pensados e elaborados.

Mais adiante temos os substantivos: quadros, pele, que pode ser a cor, pintura e óleo que nos remete aos materiais da pintura. Mais abaixo temos as cores, o marrom com os objetos que nos lembram essa cor, o branco azulado das nuvens. Fala das formas e do tamanho, aquele mediano. Também menciona que as obras desse pintor com seus tons amarronzados são tão agradáveis que, instintivamente, procuramos por algo nesse tom ou algo de madeira, se por acaso não encontramos esse pintor numa exposição.

Cita também alguns nomes de pintores como se estivesse em uma exposição e apontasse os que mais o agradam e por último Braque como que sendo a assinatura do quadro que acaba de apreciar.

Tanto nesse texto quanto no anterior, é a partir do jogo com a linguagem que Ponge marca pictoricamente seus textos, quebrando e recompondo elementos tirados dos nomes dos dois pintores como numa colagem, como se também quisesse revolucionar as Artes com Braque, introduzindo a colagem na Pintura, além de outros materiais (THUILLIER, 2003, p.556):

[Braque e Picasso] estiment alors qu'ils peuvent, sans briser l'unité plastique, introduire dans le tableau des lettres d'imprimerie plus ou moins sibylines. Puis ces fragments de mots deviennent vers 19121913 les morceaux de journal, de réclame, de partition musicale, de papier peint, d'étoffe, fixés directement sur la peinture: soit les premiers «colages».

Nos dois textos, as marcas pictóricas claras acontecem em meio a um jogo de desmontagem e remontagem de palavras que se assemelham a uma colagem. Ponge se faz um discípulo de Braque, fazendo a mímesis de sua técnica de trabalho. Mais do que espectador, Ponge se faz artesão. 
Braque se transforma em Bach, baroque e barques e Vulliamy se transforma, entre outros, em Voilà un ami. Ponge joga com as palavras, aqui se tornam objetos seus, para falar de seus amigos e usa seus nomes como referenciais modificados, atrelados a outras palavras com as quais reforça ainda mais o intrincado caminho até a alusão.

\section{Conclusão}

Ponge procura a linguagem que mais se adequa ao seu objeto, como coloca Vouilloux (2005, p.91) (tradução minha):

Também, um pouco como Ponge dizendo do poema que é para ele mesmo sua própria arte poética, teria a intuição de que a descrição do quadro não pode mais contar com fórmulas de uma tradição, mas inventar a cada vez (na) a língua que faz falar a obra [...]

Em muitos de seus textos toma o lugar de um pintor, trabalha como pintor, considerando-se pintor de naturezas-mortas, como relata em Méthodes. Os exemplos da prosa sobre Vulliamy e o texto sobre Braque ilustram algumas das maneiras de Ponge lidar com o tema das artes plásticas e escrever sobre elas e os pintores. Nesses textos Ponge se coloca, primeiramente, como espectador, pois acompanha a vida artística de seu tempo, marcando seus gostos, não fazendo distinção entre artistas maiores e menores como atesta também seu interesse pelo sapateiro e artista Ange Boaretto (chamado Ange). O poeta observa seus amigos, seu modo de trabalho, suas obras e tece considerações sobre eles. Considerações em forma de prosa que visa a um exame sob vários ângulos da plástica do seu "objeto" e faz dele uma obra. Assim como faz uso de seu conhecimento técnico sobre a cor em La Mounine, faz aqui nesses dois textos uso do nome próprio, fazendo com as palavras marcas pictóricas em seus escritos.

\section{REFERÊNCIAS}

BONNEFOY, Y. Poésie et peinture 1993-2005. Tours: William Blake \& Co., 2005.

CAPLLONCH, B. B. De la plausibilitat referencial del llenguatge poetic: Francis Ponge, o el cas d'una poetica referencialista. Tese (Doutorado) - Universitat Pompeu Fabra, Barcelona, Espanha, 2009. 
HORÁCIO. Ars Poetica. In: Aristóteles, Horácio, Longino. A poética clássica. Tradução de Jaime Bruna. São Paulo: Cultrix, 1988.

LESSING, G. E. Laocoonte ou sobre as fronteiras da pintura e da poesia. Introdução, tradução e notas de Márcio Seligmann-Silva. São Paulo: Iluminuras, 1998.

LICHTEnsteIn, J. (Org.). A Pintura: o paralelo das artes. São Paulo: Editora 34, 2005 (v.7).

MOTTA, L. T. da. Francis Ponge: o objeto em jogo. São Paulo: Iluminuras, 2000.

PIERROT, J. Francis Ponge. Paris: José Corti.

PONGE, F. O partido das coisas. São Paulo: Iluminuras, 2000.

. Méthodes. Paris: Gallimard, 1961.

. Le peintre à l'étude. Paris: Gallimard, 1948.

Le parti pris des choses. Paris: Gallimard, 1942.

PRAZ, M. Literatura e artes visuais. São Paulo: Cultrix, 1982.

THUILLIER, J. Histoire de l'art. Paris: Flammarion, 2003.

VOUILLOUX, B. La peinture dans le texte $\mathbf{X V I I I}^{\mathbf{e}-} \mathbf{X X}^{\mathbf{e}}$ siècles. Paris: CNRS, 2005.

Artigo recebido em 25/02/2011

Aceito para publicação em 28/06/2011 